\title{
A novel inactivating mutation of the LH/chorionic gonadotrophin receptor with impaired membrane trafficking leading to Leydig cell hypoplasia type 1
}

\author{
Adolfo Rivero-Müller 1,3,4, Iulia Potorac ${ }^{2}$, Axelle Pintiaux ${ }^{2,6}$, Adrian F Daly², \\ Albert Thiry ${ }^{7}$, Catherine Rydlewski ${ }^{8}$, Michelle Nisolle ${ }^{6}$, Anne-Simone Parent ${ }^{2,9}$, \\ Ilpo Huhtaniemi ${ }^{1,5}$ and Albert Beckers ${ }^{2}$ \\ 1Department of Physiology, Institute for Biomedicine, University of Turku, Turku, Finland, \\ ${ }^{2}$ Department of Endocrinology, Centre Hospitalier Universitaire de Liège, Université de Liège, Domaine \\ Universitaire du Sart-Tilman, 4000 Liège, Belgium, ${ }^{3}$ Faculty of Natural Sciences and Technology, \\ Åbo Akademi University, Turku, Finland, ${ }^{4}$ Department of Biochemistry and Molecular Biology, Medical University \\ of Lublin, 20-093 Lublin, Poland, ${ }^{5}$ Department of Surgery and Cancer, Imperial College London, Institute of \\ Reproductive and Developmental Biology, Hammersmith Campus, London, UK, Departments of ${ }^{6}$ Gynecology and \\ ${ }^{7}$ Anatomopathology, CHU de Liège, Université de Liège, Domaine Universitaire du Sart-Tilman, 4000 Liège, \\ Belgium, ${ }^{8}$ Department of Medical Genetics, Erasme Hospital, Brussels, Belgium and ${ }^{9}$ Department of Pediatrics, \\ CHU de Liège, Université de Liège, Domaine Universitaire du Sart-Tilman, 4000 Liège, Belgium
}

\author{
Correspondence \\ should be addressed \\ to A Beckers \\ Email \\ albert.beckers@chu.ulg.ac.be
}

\begin{abstract}
Objective: The LH/chorionic gonadotrophin receptor (LHCGR) is a G protein-coupled receptor (GPCR) that plays a central role in male sexual differentiation, regulation of ovarian follicular maturation, ovulation and maintenance of corpus luteum and pregnancy, as well as maintenance of testicular testosterone production. Mutations in the LHCGR gene are very rare. The aim of this work was to study the clinical and molecular characteristics of a rare familial LHCGR mutation.

Methods: Five affected members of a family, including a phenotypically female, but genotypically male (46,XY), patient with Leydig cell hypoplasia type 1 and four genotypically female siblings with reproductive abnormalities, were studied genetically. Cell trafficking studies as well as signalling studies of mutated receptor were performed.

Results: The five affected patients were all homozygous for a novel mutation in the LHCGR gene, a deletion of guanine in position 1850 (1850delG). This resulted in a frameshift affecting most of the C-terminal intracellular domain. In vitro studies demonstrated that the $1850 \mathrm{delG}$ receptor was completely incapable of transit to the cell membrane, becoming trapped within the endoplasmic reticulum. This could not be rescued by small-molecule agonist treatment or stimulated intracellularly by co-expression of a yoked human chorionic gonadotrophin.

Conclusions: This novel LHCGR mutation leads to complete inactivation of the LHCGR receptor due to trafficking and signalling abnormalities, which improves our understanding of the impact of the affected structural domain on receptor trafficking and function.
\end{abstract}

\section{Introduction}

In humans, the luteinizing hormone/chorionic gonadotrophin receptor (LHCGR) transduces intracellular signalling upon activation by either of its ligands: LH or human chorionic gonadotrophin (hCG), secreted by the pituitary gland and placenta respectively. In men, the LHCGR is responsible for the stimulation of testosterone (c) 2015 European Society of Endocrinology Printed in Great Britain
Published by Bioscientifica Ltd. 
production by fetal and adult Leydig cells, thereby promoting the differentiation and maturation of the male extragonadal phenotype in response to hCG during embryogenesis and later in response to post-natal $\mathrm{LH}$ secretion.

The importance of the LHCGR in male phenotypic development is well known, as individuals carrying partially inactivating mutations of the LHCGR present with hypogonadal phenotypes of variable severity, ranging from micropenis to hypospadias (Leydig cell hypoplasia type 2 (LCHT2)). Karyotypic males carrying completely inactivating LHCGR gene mutations have a disorder of sexual differentiation (DSD) comprising the complete absence of male differentiation (i.e. they have female external genitalia) due to absent androgenisation during fetal development (termed Leydig cell hypoplasia type 1 (LCHT1)) (1). In women, inactivating LHCGR mutations do not affect the early normal development of primary and secondary sexual characteristics, but they cause primary or secondary amenorrhoea and infertility due predominantly to a lack of pre-ovulatory follicular maturation and ovulation $(2,3)$. Probably, due to their profound effect on fertility in both sexes, severe inactivating mutations of the $L H C G R$ gene present very rarely in a clinical setting. Thorough analysis of rare mutations reveals important information regarding structurefunction relationships of the LHCGR and related G protein-coupled receptors (GPCRs).

Herein, we report a rare case of LCHT1 due to a novel mutation in the LHCGR gene that reveals significant functional consequences due to impaired receptor trafficking and signalling.

\section{Patient and methods}

\section{Case report}

A 35-year-old North African patient was referred to the gynaecological unit for primary amenorrhoea. She was the fourth child of the kindred comprising eight members (7F, 1M), and consanguinity was present as her parents were first cousins. Two sisters had apparently normal secondary sexual development: one had four offspring, while the other sister, although she had no children, had normal pubertal development and regular menstruation. The brother was in good health and had three healthy children. The other four sisters all presented with reproductive system abnormalities: three had primary amenorrhoea and variable breast development, while one had irregular menstrual cycles and normal breast development. All four had a normal female karyotype 46,XX. Further detailed gynaecological and endocrine investigations were declined.

On examination, the patient had a eunuchoid habitus, pre-pubertal breast development (B1), and scant axillary and pubic hair (P2). Acne and hirsutism were absent and body weight was normal. On gynaecological examination, normal female external genitalia were present, the vagina was blindended and no pelvic masses were palpable.

Biochemistry results found very low levels of oestradiol $(<20 \mathrm{pg} / \mathrm{ml}$, postmenopausal value) and testosterone ( $<0.03 \mathrm{ng} / \mathrm{ml}$; normal range (NR): 0.06-0.86) with high LH (22.70 mU/l; NR: 1.3-10.1) and normal FSH levels (12 mU/l; NR: 1.4-13.6). Thyroid hormones, prolactin, cortisol and DHEA-S levels were within normal ranges. Marked osteoporosis was found on DEXA ( $T$-score: -3.99 (trabecular); -3.16 (cortical)) with a stress fracture in the left ankle. Abdomino-pelvic ultrasound and MRI revealed absent uterus and other Müllerian structures. Apart from the small vaginal cavity $(3.0 \times 5.0 \mathrm{~cm})$, bilateral masses $(2.0 \times 1.5 \times 1.0 \mathrm{~cm})$ in the superior inguinal canal were found, consistent with testicular remnants. The karyotype was $46, \mathrm{XY}$.

The patient underwent bilateral gonadectomy; histology confirmed testicular tissue comprising immature seminiferous tubules with a thickened basement membrane and no lumen (Fig. 1A), fibroblast-like interstitial cells and epididymal structures in the tissue adjacent to the gonad. Immunohistochemistry staining with anti-inhibin- $\alpha$ (CMC28340021, Cell Marque Corporation, Rocklin, CA, USA) and anti-3ßhydroxysteroid dehydrogenase (anti-3 $\beta$ HSD) (sc-30820, 1:200, Santa Cruz Biotechnology, Inc.) antibodies was performed in the patient tissue and in normal testicular tissue to illustrate the presence of Leydig cells. Immunohistochemistry staining with anti-placental alkaline phosphatase (anti-PLAP) antibodies (CMC26640021, Cell Marque Corporation), a marker of germ cells, was also performed.

\section{Mutation detection}

Following counselling, the patient consented to genetic studies. DNA was extracted from peripheral blood leukocytes by phenol-chloroform extraction. The LHCGR coding sequence was amplified by PCR followed by direct sequencing of PCR products. Exons 1-11 were amplified by one touchdown PCR. The PCR products were purified with ExoSAP-IT (USB Corporation, Cleveland, OH, USA) according to the manufacturer's instructions and then sequenced with the BigDye Terminator Ready Reaction Mix v.1.1 (Applied Biosystems). The four sisters with 


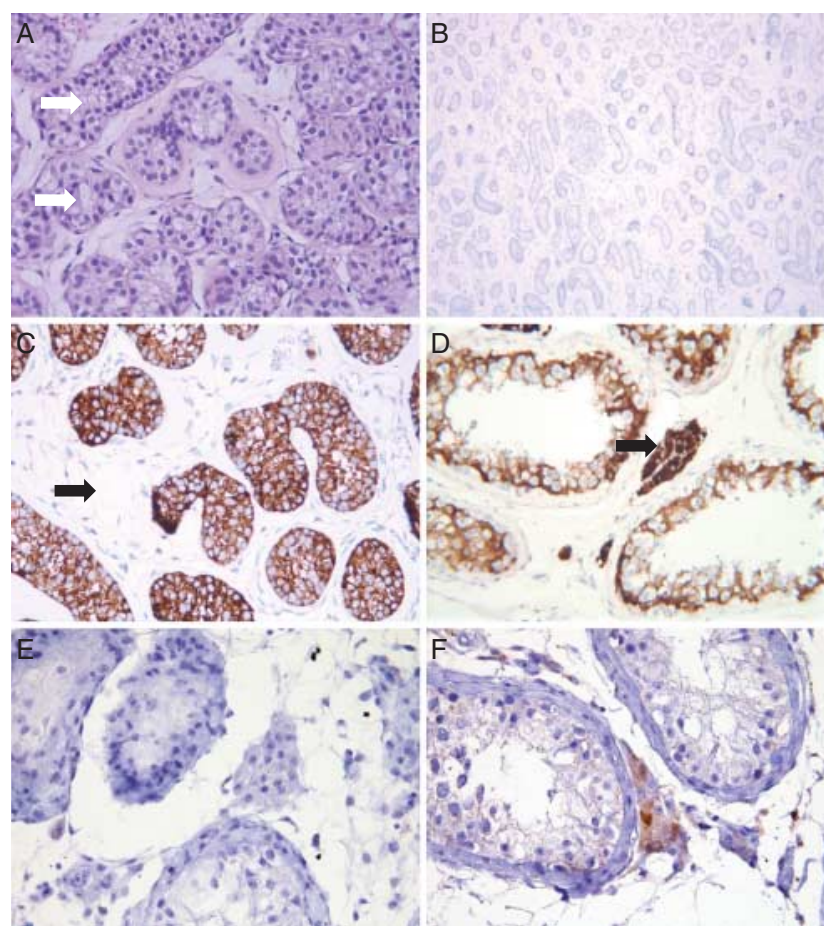

\section{Figure 1}

Histological section of the testicular tissue: (A) hematoxylin and eosin staining $(200 \times)$ showing immature seminiferous tubules with no lumen and a thickened basement membrane (white arrows). (B) Immunostaining with an anti-placental alkaline phosphatase (anti-PLAP) antibody $(100 \times)$ showing absence of germ cells. (C) Immunostaining with an anti-inhibin- $\alpha$ antibody (200X; brown) showing positivity of Sertoli cells and absence of Leydig cells (black arrow). (D) Immunostaining with an antiinhibin- $\alpha$ antibody ( $250 \times$; brown) of normal testicular tissue showing positivity of Sertoli cells and also of Leydig cells (black arrow). (E) Immunostaining with anti-3ßhydroxysteroid dehydrogenase (anti-3ßHSD) $(400 \times)$ showing absence of Leydig cells. (F) Immunostaining with anti-3ßHSD $(400 \times$, brown) of normal testicular tissue showing presence of Leydig cells.

menstrual anomalies also underwent counselling and genetic sequencing of the LHCGR gene.

\section{Construction of mutant cDNA expression vectors}

The HA-tagged WT human LHCGR cDNA cloned into the pSG5 vector (4) was mutated as described elsewhere (manuscript in preparation). Briefly, PCR was performed using KOD Xtreme polymerase (Millipore, Espoo, Finland) with the primers described in Supplementary Table S1, see section on supplementary data given at the end of this article and then digested with DpnI to remove the template plasmid. The linear PCR product was joined by recombineering (see Supplementary material for full sequences as well as Supplementary Figures S1 and S2).

Two positive clones carrying the mutated LHCGR sequence and two WT clones underwent sequencing to verify the normal and mutated sequences, the latter being referred to henceforth as HA-1850delG. These two clones for each WT and mutant were used for all downstream procedures. They were then amplified in Escherichia coli and purified using a maxiprep kit (Macherey-Nagel, Düren, Germany). The purified plasmids were used for transfection of HEK293-GS cells (see below) using JetPEI (Polyplus, Illkirch, France).

\section{Signal transduction}

The HEK293 cells used in this study have been stably transfected with a sensor plasmid for cAMP (GloSensor22F, Promega). This cell line, hereafter referred to as HEK293-GS cells, was cloned for its sensitivity and stability in the detection of cAMP generated by forskolin (Sigma) treatment as reported previously (5).

HEK293-GS cells in 24-well plates were transfected with either the WT HA-LHCGR or the HA-1850delG plasmids. Transfected HEK293-GS cells were incubated for $48 \mathrm{~h}$ in normal medium (DMEM-F12 conditioned with $10 \%$ FCS) before the analysis of cAMP generation.

Cells were then analysed for their responsiveness to recombinant human LH (rhLH) or hCG, $50 \mathrm{nM}$, in 50\% DMEM/50\% $\mathrm{CO}_{2}$-independent medium (Invitrogen) and 2\% GloSensor reagent (Promega). The generation of cAMP directly correlates with the activation of the GloSensor luciferase reporter system. Luminescence was recorded in a Victor plate reader (Wallac, Turku, Finland) at intervals of $10 \mathrm{~s}$ for over $60 \mathrm{~min}$ (kinetic measurements). The recorded values were presented as luminescence per second.

\section{Trafficking studies}

To detect whether the mutant receptor localises to the cell membrane, we used a standard flow cytometry protocol, where, in non-permeabilised cells, the detection of the receptor can only be achieved if the receptor is expressed on the cell membrane, while, in permeabilised cells, the presence of the receptor will be detected by the antibody as to whether it is on the cell membrane or located intracellular (6). HEK293-GS cells transfected with either HA-WT or HA-1850delG LHCGR plasmids were then incubated with a primary antibody (goat anti-HA; Bethyl, Helsinki, Finland) against the HA tag, for $30 \mathrm{~min}$. The medium was removed and the cells were washed twice with 
PBS, and then detached from the plates before incubation with a fluorescent-tagged secondary antibody (Alexa Fluor594 donkey anti-goat, Molecular Probes, Helsinki, Finland) and incubated for $30 \mathrm{~min}$ in the presence of $4 \%$ serum. The cells were then collected and analysed through a flow cytometer (FACScalibur, BD, Vantaa, Finland) for the membrane-bound fluorescence in the red filter (gate FL-2) compared with the green filter (FL-1), the latter representing auto-fluorescence. Positive events, within the FL-2 gate (marked area), are presented as the percentage of the total number of events (20000 cells/sample). Untransfected cells were used as a negative control and HA-WT LHCGRtransfected cells as a positive control.

\section{Immunocytochemistry}

Transfected and untransfected cells were fixed in 4\% PFA for 10 min and washed twice with PBS-T (0.1\% tritonX100) to permeabilise the cell membrane. Fixed cells were then blocked with $4 \%$ BSA in PBS, and then incubated with an anti-HA antibody (PBS-T plus 4\% normal goat serum (NGS)) for $1 \mathrm{~h}$ at room temperature, washed twice with PBS-T and incubated with the fluorescent anti-goat secondary antibody for $1 \mathrm{~h}$, washed twice and mounted in VectaShield with DAPI (Vector Laboratories, Peterborough, UK). Samples were analysed under a fluorescent microscope (Zeiss AxioVert 200M).

\section{Intracellular activation and rescuing of the mutant LHCGR}

The yoked hCG (yhCG), a fusion of both hCG subunits that forms an active hCG molecule (kindly provided by Prema Narayan (7)), was co-transfected with the LHCGRs (mutant and WT) to HEK293-GS cells as described earlier in this report. Then, $48 \mathrm{~h}$ after transfection, cAMP generation was measured as described earlier in this report without further addition of ligand.

The HEK293-GS cells were transfected with either the WT LHCGR or the 1850delG plasmids and were incubated for $24 \mathrm{~h}$ in the presence of the allosteric LHCGR agonist, Org 42599 (kindly provided by Dr Claire Newton (8)), and cAMP generation was measured before (agonist overnight $(\mathrm{ON})$ ) or after addition of ligand (100 ng of recombinant human CG (rhCG)).

\section{Endoplasmic reticulum stress assay}

Endoplasmic reticulum (ER) stress was determined by the transcriptional activity of the ER stress element (ERSE), detected by the Cignal ERSE Reporter Luciferase Assay
(SA Bioscience Qiagen). The ERSE reporter assay is based on a mixture of an ERSE-responsive firefly luciferase construct and a constitutively expressed Renilla luciferase construct - as a transfection control. Luciferase activities were measured using the Dual Luciferase assay kit (Promega) using a plate reader (EnSight, PerkinElmer, Turku, Finland), and the results are expressed as a ratio of the ERSE firefly luciferase reporter to Renilla luciferase. HEK293 cells were transfected in 96-well plates with a negative control (pcDNA), or a positive control, or an ERSE reporter plus either the WT LHCGR or the 1850delG-LHCGR for $48 \mathrm{~h}$ before analysis. Every condition was performed in triplicate and the assays were performed at least twice. Data are expressed as mean \pm s.D. $(n=3)$.

\section{Results}

\section{Immunohistochemistry staining}

Immunohistochemistry staining with anti-inhibin- $\alpha$ and anti-3ßHSD antibodies showed the absence of Leydig cells (Fig. 1C and E) compared with normal testicular tissue (Fig. 1D and F). Germ cells were also absent on immunohistochemistry staining with anti-PLAP antibodies (Fig. 1B).

\section{Mutation detection}

Sequencing of the LHCGR gene revealed deletion of a guanine at position 1850. This deletion led to a frameshift mutation where the original C-terminal 83 coded amino acids are replaced by 21 new amino acids (starting from p.Cys617Leu) followed by a termination codon (Supplementary Figure S2 and Supporting material). The patient and the four $46, \mathrm{XX}$ sisters with menstrual anomalies were homozygous for the mutation.

We recreated an identical mutant (1850delG) by modifying a HA-tagged LHCGR cDNA cloned into a mammalian expression vector (pSG5). The site-directed deletion was verified by sequencing (Supporting material). The addition of the HA-tag is important for expression and localisation analyses. The amino acid changes in the 1850delG when compared with the WT LHCGR as well as a schematic representation of the changes in the C-terminal of the mutant receptor (Figure S2) when compared with the WT receptor (Supplementary Figure S1) are described in the Supplementary Material.

\section{Signal transduction and protein localisation}

Cells transfected with the HA-1850delG expression vector showed no cAMP generation in response to any of the 
A

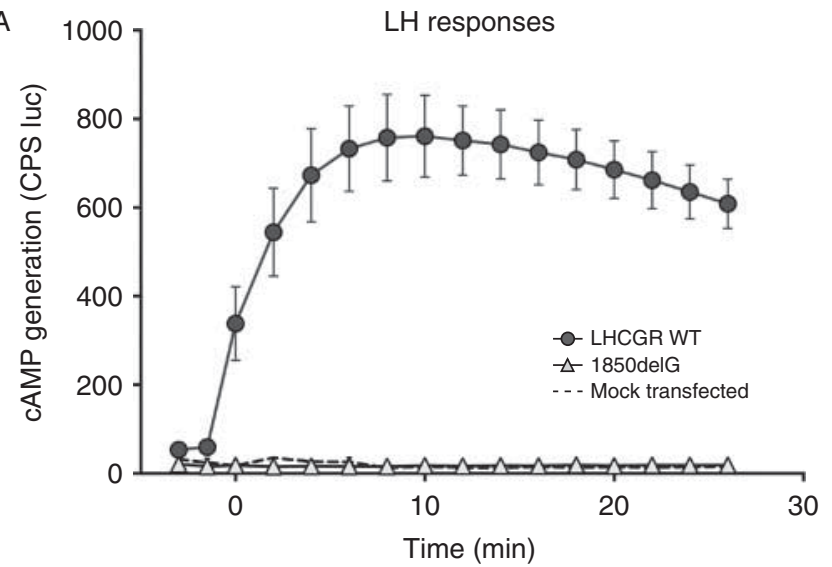

B

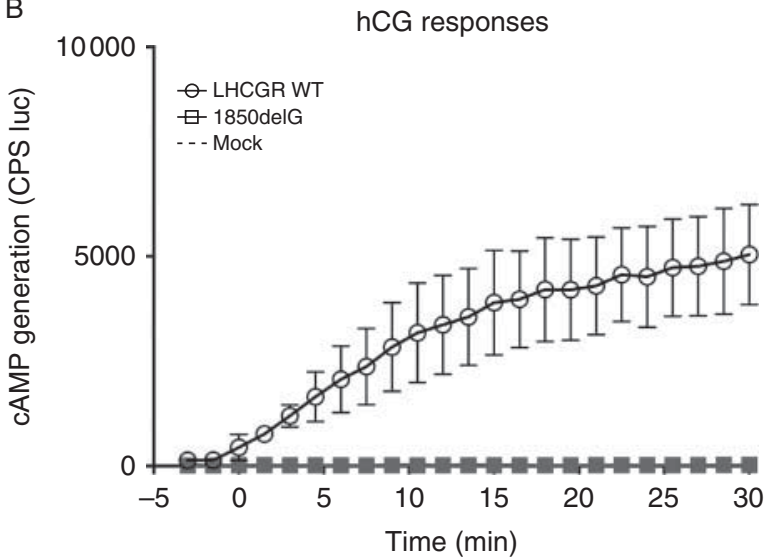

Figure 2

CAMP generation by the WT and mutant LHCGRs. HEK293-GS cells were transfected with a plasmid carrying either the WT HA-LHCGR (WT) or the HA-1850delG LHCGR mutant (1850delG). Cells were stimulated with recombinant human LH (rhLH) or hCG at different concentrations although only the highest concentration is shown (100 ng) and the generation of CAMP (mean \pm s.D.) was recorded in a kinetic mode using a luminometer. The data are expressed as area under the curve. The WT receptor responded to both,

(A) LH and (B) hCG, while the 1850 delG did not respond to either of them at any given concentration ( $A$ and $B$ ).

tested concentrations of rhLH or rhCG, unlike those expressing the WT receptor (Fig. 2). This lack of signal transduction corresponds well to the patient's phenotype of severely impaired testosterone production.

In order to study the effects of the mutation on receptor localisation, trafficking and signalling, we tested the presence of the mutant receptor at the cell membrane using an antibody against the extracellular N-terminal HA-tag, analysed by flow cytometry and immunocytochemistry. While the WT HA-LHCGR was detected on the cell membrane of transfected cells, the HA-1850delG mutant was completely absent from the cell membrane (Fig. 3 top row and Fig. 4 first and second rows), but could be detected in permeabilised cells (Fig. 3 bottom row and Fig. 4 third and fourth rows), which showed that the receptor was normally expressed, but its trafficking to the cell membrane was compromised.

The accumulation of misfolded proteins in the ER causes the ER stress response that is a cellular process triggered in order to protect the cells from further stress injury (reviewed in (9)). Indeed, transfection with the 1850delG mutant resulted in more than twice the ER-stress caused by transfection of either the WT counterpart or an empty plasmid (pcDNA) (Fig. 5C).

We attempted to activate the receptors at the ER by co-expressing a yhCG, a fusion of both hCG subunits that forms an active hCG molecule (7). We hypothesised that,

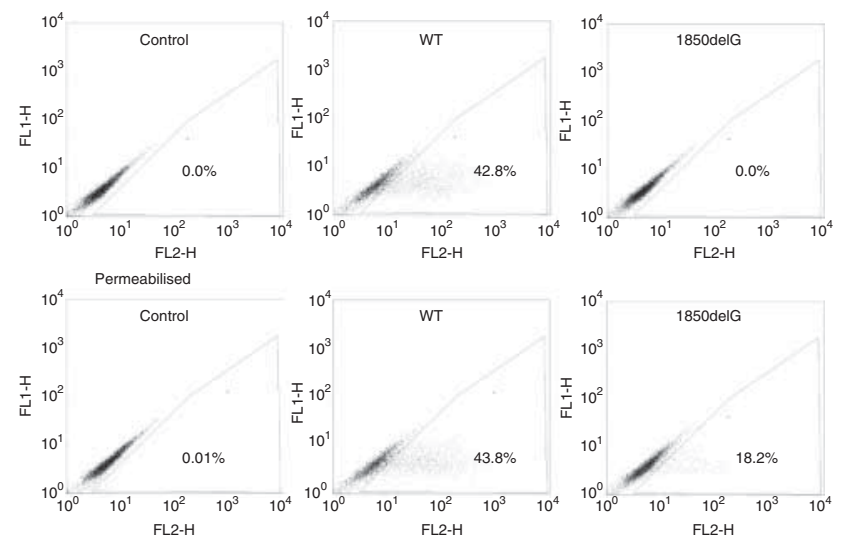

\section{Figure 3}

Membrane localisation of the mutant receptor. Cells transfected with a plasmid carrying either the WT HA-LHCGR (WT) or the HA-1850delG LHCGR mutant (1850delG) for $48 \mathrm{~h}$ were incubated with an antibody against the N-terminal HA-tag and a red fluorescent-labelled secondary antibody before being analysed by flow cytometry. The total number (\%) of fluorescent-labelled cells is presented within FL-2 gate, selected area. (A) WT HA-LHCGR showing membrane localisation of the receptor; while the HA-1850delG shows no membrane localisation, the control is represented by untransfected cells. (B) The HA-1850delG mutant was expressed, although at lower levels when compared with WT LHCGR, but was retained intracellularly as analysed after permeabilisation and immunofluorescent staining of the cells. Percentages shown represent the number of positive cells (gated in FL-2) to immunofluorescent staining by flow cytometry. The total number of events for each sample was 20000 . 


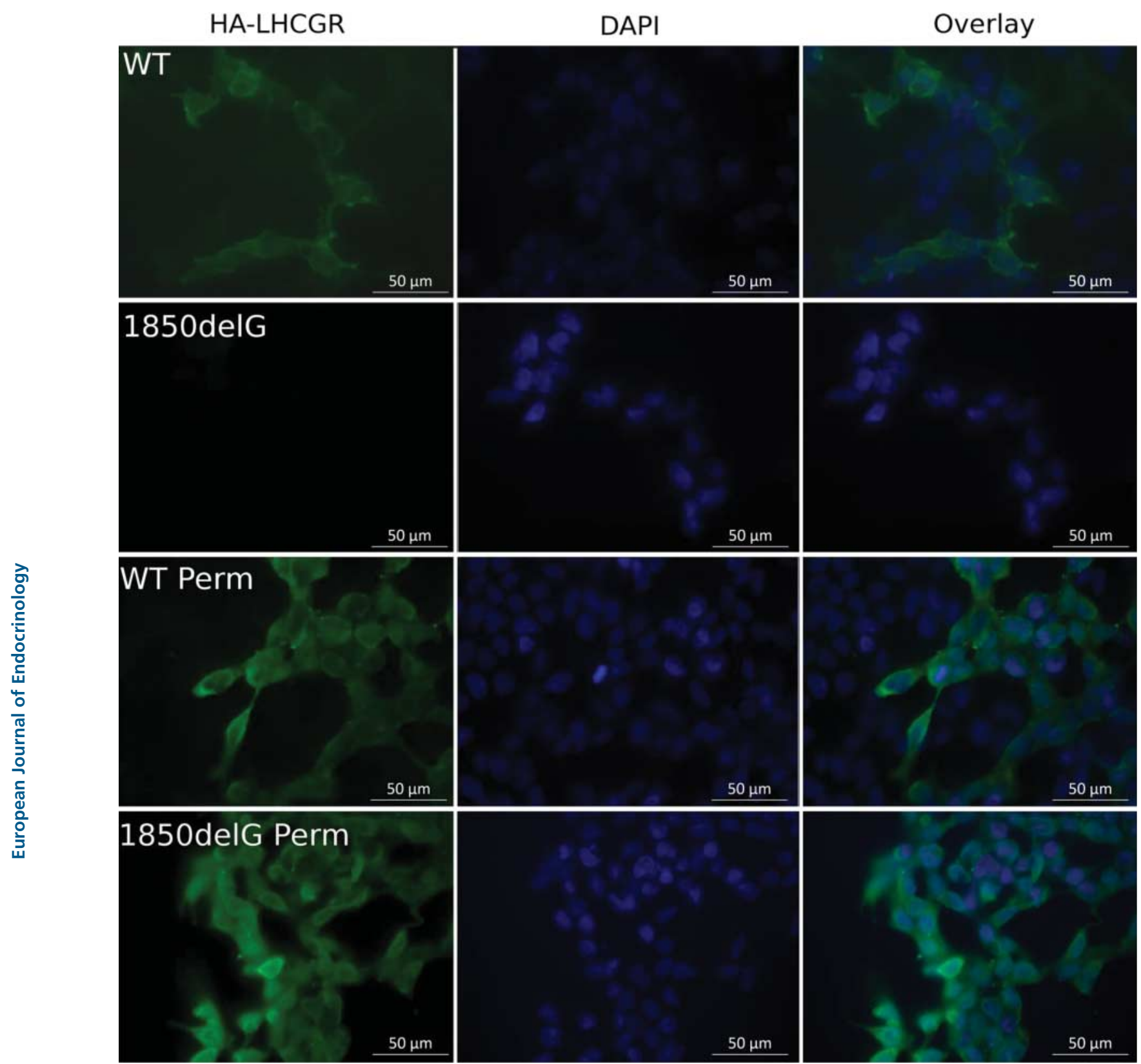

\section{Figure 4}

Membrane localisation of the mutant receptor. Cells transfected with a plasmid carrying either the WT HA-LHCGR (WT) or the HA-1850delG LHCGR mutant (1850delG) were incubated with an antibody against the N-terminal HA-tag before (upper rows) or after (lower rows) fixation and permeabilisation (Perm). A fluorescent-labelled secondary antibody was used for

although the 1850delG LHCGR mutant was unable to traffic to the cell membrane, it could still potentially be activated in the ER by ligands. Co-expression of the yhCG resulted in cAMP production in the WT LHCGR but no detection. The WT HA-LHCGR shows membrane and intracellular localisation, while the 1850delG mutant could only be detected in the intracellular compartment (1850delG Perm). Cell nuclei were counterstained with DAPI prior to mounting. Overlay of the two channels is presented in the third column.

response was found with the 1850delG mutant (Fig. 5A). We are unable to know if the response detected in the co-expression of yhCG/WT-LHCGR occurred in the intracellular compartment or after the yhCG was itself secreted. 
Cells expressing the mutant receptor did not produce increased cAMP after overnight incubation with the allosteric LHCGR agonist, Org 42599, either alone or in combination with hCG. In contrast, cells expressing the WT LHCGR responded to both with increased cAMP generation (Fig. 5B).

\section{Discussion}

We present a case of a family with a newly described inactivating mutation of the LHCGR gene. It reveals a novel deletion of nucleotide 1850G, leading to a frameshift alteration of amino acids 617-637 (situated in the 7th transmembrane domain (TM7)) and a premature stop codon. This modifies the receptor's C-terminal sequence from that of the WT receptor, by replacing the last 83 amino acids, including all of the intracellular tail, by an incorrect and truncated
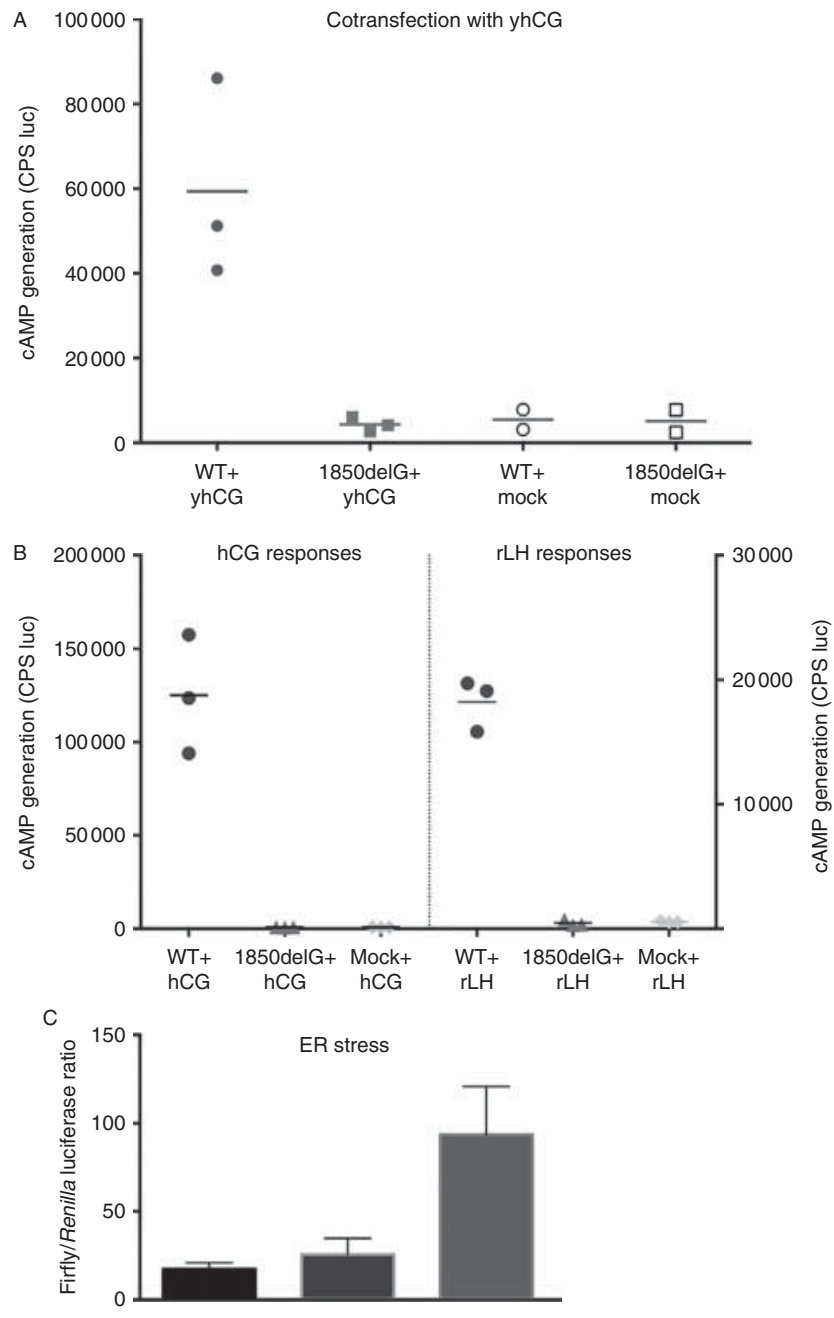

Several mutations hampering LHCGR function have been described to date. The phenotype depends on the underlying sex of the patient and also on the degree of receptor inactivation caused by the mutation. At the severe end of the spectrum are exceptionally rare cases of inactivating mutations of $L H C G R$, which result in a nearcomplete lack of masculine development and pseudohermaphroditism, classified as LCHT1, as in the propositus of this family. In the case of partially inactivating LHCGR mutations or mutants that are poorly sensitive to LH but responsive to hCG (10), genotypic $(46, \mathrm{XY})$ males can have a spectrum of disorders from micropenis to hypospadias (1). These can share some similarity to mutants of the LH beta subunit (LHB) $(11,12,13,14,15)$ and all are categorised as LCHT2. The reason for such normal prenatal but abnormal postnatal phenotype is due to the role played by placental hCG during fetal development in primates, including humans. The phenotype of the affected female siblings who were also homozygous for

\section{Figure 5}

Rescue of 1850 delG mutant receptor. (A) HEK293-GS cells were co-transfected with a plasmid carrying the yoked hCG (yhCG) and either the WT HA-LHCGR (WT) or the HA-1850delG plasmids. At $48 \mathrm{~h}$ after transfection the autocrine generation of CAMP was measured by kinetics mode. While the WT LHCGR responded, the 1850delG mutant showed no CAMP generation similar to the negative control. (B) Cells transfected with either the WT or the 1850delG mutant plasmids were incubated with Org 42599 agonist overnight (ON) followed by hCG stimulation (100 ng). The WT LHCGR responded to the small molecule antagonist by producing CAMP while the 1850 delG mutant showed no response, equal to negative vehicle controls. Similarly, preincubation with the agonist did not rescue the responsiveness of the 1850delG mutant to hCG (agonist + hCG) as the CAMP levels were equal to the mock-transfected control. Values are expressed as area under the curve of 30 min kinetic measurements. (C) Endoplasmic reticulum (ER)-stress was measured by the Cignal ER stress element (ERSE) Reporter Luciferase Assay. The results are expressed as ratio of firefly luciferase reporter to Renilla luciferase after background (untransfected cells) subtraction. Transfection of the negative control (pcDNA) and WT LHCGR plasmids to HEK293 cells resulted in almost no ERSE activation while transfection with the 1850 delG-LHCGR resulted in more than twice the ERSE activation. Every condition was performed in triplicate and the assays were performed at least twice. Data are expressed as mean \pm s.D. $(n=3)$. 
the LHCGR mutation echoes that of previously described cases, having either amenorrhoea or oligomenorrhoea plus variable breast development.

The patient described herein belongs to the LCHT1 category, with an immature female phenotype despite the 46,XY karyotype. To date, 17 LHCGR mutation families leading to disorders of male sex development (with phenotypic female appearance) have been described. These mutations were due to different mechanisms: substitutions, small or large deletions and insertions (16).

The clinical presentation of the propositus is similar to other reported cases: eunuchoid habitus, the absence of secondary sex characteristics and the presence of intraabdominal testes. The testicular pathology is explained by the androgen-independent differentiation of the primordial gonad in males by expression of the $S R Y$ gene located on the Y chromosome. Thereafter, the primordial gonad acquires a tubular structure with Sertoli cells beginning to secrete anti-Müllerian hormone. It is this hormone that signals the regression of the Müllerian ducts, the derivatives of which would otherwise form part of the female internal reproductive system. However, after this initial stage, testicular differentiation and development are dependent on testosterone secretion by the Leydig cells. The fetal Leydig cells begin steroidogenesis in a gonadotrophin-independent manner, leading to development of the vas deferens and epididymis from the Wolffian duct. This process is achieved even under low androgen receptor (AR) stimulation, as in patients with complete androgen insensitivity syndrome (CAIS) but residual AR activity, who have remnants of epididymis and vas deferens (17). Similar to cases of CAIS, in our patient, germ cells were absent on histological examination. This is most probably due, on one hand, to the limited AR stimulation. In a recent study, Kaprova-Pleskacova et al. (18) found that survival of germ cells in CAIS patients was significantly related to the residual AR activity. On the other hand, germ cell numbers in CAIS patients decrease with age, with a rapid decline after the first year of life (19).

Animal models of inactivating LHCGR mutations $(20,21)$ exhibit a different phenotype from that of the human, which is understandable given the lack of CG in non-primates apart from equines $(22,23)$. At birth, male mice with homozygous inactivating mutations of the $\mathrm{Lhcgr}$ have the same phenotype as their WT littermates. It is only postnatally that a low testosterone secretion and impaired reproductive tract development set apart the former from the latter. An LH/LHCGR-independent alternative mechanism for embryonic testosterone generation is present in rodents (24) and a basal level of testosterone is generated in Lhcgr-knockout mice (LuRKO) resulting in incomplete spermatogenesis at 12 months of age (25).

At the molecular level, the mutation described herein seems to present a particularly severe phenotype. Despite being expressed, albeit at lower levels than the WT, the mutant LHCGR is incapable of signal transduction as it is unable to reach the cell membrane. Sequestered, misfolded proteins in the ER trigger the unfolded protein response (UPR) and reduce gene expression (26), which may well explain the molecular pathogenesis of this 1850delG mutant. A point mutant of the LHCGR A593P, leading to a phenotype of male DSD (27), and S616Y, leading to LCHT2 (28), are also retained in the ER, but both can be rescued by the allosteric LH receptor agonist Org 42599 (8), which induced surface expression of these receptors and further led to signal transduction (8). In marked contrast, in our case, overnight incubation with the pharmacological chaperone alone or in combination with hCG had no effect on cAMP production, probably due to the severe alteration of the amino acid sequence, which prevents the possibility of correct tertiary structure folding.

The LHCGR is a member of GPCR class A (29). Export from the ER to the cell membrane is the last event in intracellular trafficking of GPCRs and it is a highly regulated event where quality-control mechanisms ensure that receptors are properly folded and glycosylated before further processing (reviewed in (30)). The structural determinants for this trafficking event in GPCRs often have led to changes in a common motif located towards the cytoplasmic end of the TM7, NPxxY, part of the larger conserved NSxxNPxxY sequence (29). The NPxxY motif of GPCRs seems to introduce, due to the proline residue, a kink in the $\alpha$-helix with a flexible 'hinge' region (31), which is important in receptor activation (32). Mutants in this region have also been reported for the LHCGR (33), although mutations elsewhere that retain the receptor at the ER also exist. Mutations located in TM domains or even in the extracellular regions of the LHCGR have been reported $(34,35)$. However, in most of the cases mentioned, the mutant receptors had some degree of membrane expression, which is not the case for the 1850delG mutant. The large anomaly introduced by the 1850delG leads to the transcription of a protein that probably folds incorrectly, and the quality control mechanisms of the ER therefore trigger its retention and degradation.

Truncation of the rat LHCGR at residue 616 (human equivalent 637) with 11 residues left in the cytoplasmic tail, originally of 69 residues, leads to impaired receptor expression on the cell membrane, which is not the case for truncations further downstream at residues 631 (human 
equivalent 652) or 653 (human equivalent 674) (33). The reduced expression could be due to the fact that the two cysteine residues 621 and 622 (human equivalents 643 and 644) are eliminated in the 616 truncation. These palmitoylated residues seem to be involved in receptor localisation, as well as ligand-bound maintenance on the cell membrane $(36,37)$.

Numerous mutagenesis studies have been performed on the conserved NSxxNPxxY domain of various GPCRs showing that this domain is also important for signal transduction ( $G$ protein activation), ligand binding and receptor post-signalling sequestration $(38,39,40)$. The alteration found in our case begins two amino acids before the NPxxY motif and completely modifies its structure (Supporting material Figures S1 and S2, see section on supplementary data given at the end of this article) in a manner that leads to a signalling deficiency, as none of the rescuing experiments resulted in 1850delG receptor stimulation.

LHCGR-1850delG is a novel frameshift mutant reported in this receptor. The resulting phenotype and molecular analyses are in agreement that this receptor is completely inactive. The receptor is unable to transit to the cell membrane, thus unable to contact with its ligands (LH or hCG) and most likely incapable of signalling, resulting in the LCHT1 phenotype.

\section{Supplementary data}

This is linked to the online version of the paper at http://dx.doi.org/10.1530/ EJE-14-1095.

\section{Declaration of interest}

The authors declare that there is no conflict of interest that could be perceived as prejudicing the impartiality of the research reported.

\section{Funding}

This study was supported by the Fonds d'Investissement pour la Recherche Scientifique du Centre Hospitalier de Liège.

\section{Patient consent}

Informed consent was obtained from the patient for publication of the case report and the accompanying images.

\section{Author contribution statement}

A Rivero-Müller, I Potorac and A Pintiaux contributed equally to this work. I Huhtaniemi and A Beckers contributed equally to the conceptualisation of this work.

\section{Acknowledgments}

The authors would like to thank Alice Marquet, Stéphanie Maquet, Lione Masset and Dr Chantal Humblet of the GIGA histology and immunohistology facility, Liège, Belgium for excellent technical assistance.

\section{References}

1 Themmen APN \& Huhtaniemi IT. Mutations of gonadotropins and gonadotropin receptors: elucidating the physiology and pathophysiology of pituitary-gonadal function. Endocrine Reviews 200021 551-583. (doi:10.1210/edrv.21.5.0409)

2 Toledo SP, Brunner HG, Kraaij R, Post M, Dahia PL, Hayashida CY \& Kremer HTAP. An inactivating mutation of the luteinizing hormone receptor causes amenorrhea in a 46,XX female. Journal of Clinical Endocrinology and Metabolism 199681 3850-3854. (doi:10.1210/jcem. 81.11.8923827)

3 Latronico AC \& Arnhold IJ. Inactivating mutations of LH and FSH receptors - from genotype to phenotype. Pediatric Endocrinology Reviews $2006428-31$.

4 Rivero-Muller A, Chou YY, Ji I, Lajic S, Hanyaloglu AC, Jonas K, Rahman N, Ji TH \& Huhtaniemi I. Rescue of defective G proteincoupled receptor function in vivo by intermolecular cooperation. PNAS 2010107 2319-2324. (doi:10.1073/pnas.0906695106)

5 Trehan A, Rotgers E, Coffey ET, Huhtaniemi I \& Rivero-Muller A. CANDLES, an assay for monitoring GPCR induced cAMP generation in cell cultures. Cell Communication and Signaling 20141270. (doi:10.1186/s12964-014-0070-x)

6 Peuhu E, Rivero-Muller A, Stykki H, Torvaldson E, Holmbom T, Eklund P, Unkila M, Sjoholm R \& Eriksson JE. Inhibition of Akt signaling by the lignan matairesinol sensitizes prostate cancer cells to TRAIL-induced apoptosis. Oncogene 201029 898-908. (doi:10.1038/ onc.2009.386)

7 Narayan P, Wu C \& Puett D. Functional expression of yoked human chorionic gonadotropin in baculovirus-infected insect cells. Molecular Endocrinology 19959 1720-1726. (doi:10.1210/mend.9.12.8614408)

8 Newton CL, Whay AM, McArdle CA, Zhang M, van Koppen CJ, van de Lagemaat R, Segaloff DL \& Millar RP. Rescue of expression and signaling of human luteinizing hormone $\mathrm{G}$ protein-coupled receptor mutants with an allosterically binding small-molecule agonist. PNAS 2011108 7172-7176. (doi:10.1073/pnas.1015723108)

9 Kaufman RJ. Stress signaling from the lumen of the endoplasmic reticulum: coordination of gene transcriptional and translational controls. Genes and Development 199913 1211-1233. (doi:10.1101/gad. 13.10.1211)

10 Gromoll J, Eiholzer U, Nieschlag E \& Simoni M. Male hypogonadism caused by homozygous deletion of exon 10 of the luteinizing hormone (LH) receptor: differential action of human chorionic gonadotropin and LH. Journal of Clinical Endocrinology and Metabolism $2000 \mathbf{8 5}$ 2281-2286. (doi:10.1210/jcem.85.6.6636)

11 Weiss J, Axelrod L, Whitcomb RW, Harris PE, Crowley WF \& Jameson JL. Hypogonadism caused by a single amino acid substitution in the $\beta$ subunit of luteinizing hormone. New England Journal of Medicine 1992326 179-183. (doi:10.1056/NEJM199201163260306)

12 Valdes-Socin H, Salvi R, Daly AF, Gaillard RC, Quatresooz P, Tebeu PM, Pralong FP \& Beckers A. Hypogonadism in a patient with a mutation in the luteinizing hormone $\beta$-subunit gene. New England Journal of Medicine 2004351 2619-2625. (doi:10.1056/NEJMoa040326)

13 Achard C, Courtillot C, Lahuna O, Meduri G, Soufir JC, Liere P, Bachelot A, Benyounes H, Schumacher M, Kuttenn F et al. Normal spermatogenesis in a man with mutant luteinizing hormone. New England Journal of Medicine 2009361 1856-1863. (doi:10.1056/ NEJMoa0805792) 
14 Lofrano-Porto A, Barra GB, Giacomini LA, Nascimento PP, Latronico AC, Casulari LA \& da Rocha Neves Fde A. Luteinizing hormone $\beta$ mutation and hypogonadism in men and women. New England Journal of Medicine 2007357 897-904. (doi:10.1056/ NEJMoa071999)

15 Basciani S, Watanabe M, Mariani S, Passeri M, Persichetti A, Fiore D, Scotto d'Abusco A, Caprio M, Lenzi A, Fabbri A et al. Hypogonadism in a patient with two novel mutations of the luteinizing hormone $\beta$-subunit gene expressed in a compound heterozygous form. Journal of Clinical Endocrinology and Metabolism 201297 3031-3038. (doi:10.1210/jc. 2012-1986)

16 Latronico AC \& Arnhold IJ. Gonadotropin resistance. Endocrine Development 201324 25-32. (doi:10.1159/000342496)

17 Hannema SE, Scott IS, Hodapp J, Martin H, Coleman N, Schwabe JW \& Hughes IA. Residual activity of mutant androgen receptors explains wolffian duct development in the complete androgen insensitivity syndrome. Journal of Clinical Endocrinology and Metabolism 200489 5815-5822. (doi:10.1210/jc.2004-0709)

18 Kaprova-Pleskacova J, Stoop H, Bruggenwirth H, Cools M, Wolffenbuttel KP, Drop SL, Snajderova M, Lebl J, Oosterhuis JW \& Looijenga LH. Complete androgen insensitivity syndrome: factors influencing gonadal histology including germ cell pathology. Modern Pathology 201427 721-730. (doi:10.1038/modpathol.2013.193)

19 Hannema SE, Scott IS, Rajpert-De Meyts E, Skakkebaek NE, Coleman N $\&$ Hughes IA. Testicular development in the complete androgen insensitivity syndrome. Journal of Pathology 2006208 518-527. (doi:10.1002/path.1890)

20 Zhang FP, Poutanen M, Wilbertz J \& Huhtaniemi I. Normal prenatal but arrested postnatal sexual development of luteinizing hormone receptor knockout (LuRKO) mice. Molecular Endocrinology 200115 172-183. (doi:10.1210/mend.15.1.0582)

21 Lei ZM, Mishra S, Zou W, Xu B, Foltz M, Li X \& Rao CV. Targeted disruption of luteinizing hormone/human chorionic gonadotropin receptor gene. Molecular Endocrinology 200115 184-200. (doi:10.1210/ mend.15.1.0586)

22 Tepper MA \& Roberts JL. Evidence for only one $\beta$-luteinizing hormone and no $\beta$-chorionic gonadotropin gene in the rat. Endocrinology 1984 115 385-391. (doi:10.1210/endo-115-1-385)

23 Carr FE \& Chin WW. Absence of detectable chorionic gonadotropin subunit messenger ribonucleic acids in the rat placenta throughout gestation. Endocrinology 1985116 1151-1157. (doi:10.1210/endo116-3-1151)

24 O'Shaughnessy PJ, Fleming LM, Jackson G, Hochgeschwender U, Reed P \& Baker PJ. Adrenocorticotropic hormone directly stimulates testosterone production by the fetal and neonatal mouse testis. Endocrinology 2003144 3279-3284. (doi:10.1210/en.2003-0277)

25 Zhang FP, Pakarainen T, Poutanen M, Toppari J \& Huhtaniemi I. The low gonadotropin-independent constitutive production of testicular testosterone is sufficient to maintain spermatogenesis. PNAS $2003 \mathbf{1 0 0}$ 13692-13697. (doi:10.1073/pnas.2232815100)

26 Xu C, Bailly-Maitre B \& Reed JC. Endoplasmic reticulum stress: cell life and death decisions. Journal of Clinical Investigation 2005115 2656-2664. (doi:10.1172/JCI26373)

27 Kremer H, Kraaij R, Toledo SP, Post M, Fridman JB, Hayashida CY, van Reen M, Milgrom E, Ropers HH, Mariman E et al. Male pseudohermaphroditism due to a homozygous missense mutation of the luteinizing hormone receptor gene. Nature Genetics 19959 160-164. (doi:10.1038/ng0295-160)
28 Latronico AC, Anasti J, Arnhold IJ, Rapaport R, Mendonca BB, Bloise W, Castro M, Tsigos C \& Chrousos GP. Brief report: testicular and ovarian resistance to luteinizing hormone caused by inactivating mutations of the luteinizing hormone-receptor gene. New England Journal of Medicine 1996334 507-512. (doi:10.1056/NEJM199602223340805)

29 Fredriksson R, Lagerstrom MC, Lundin LG \& Schioth HB. The G-protein-coupled receptors in the human genome form five main families. Phylogenetic analysis, paralogon groups, and fingerprints. Molecular Pharmacology 200363 1256-1272. (doi:10.1124/mol.63.6. 1256)

30 Dong C, Filipeanu CM, Duvernay MT \& Wu G. Regulation of G proteincoupled receptor export trafficking. Biochimica et Biophysica Acta 2007 1768 853-870. (doi:10.1016/j.bbamem.2006.09.008)

31 Findlay J \& Eliopoulos E. Three-dimensional modelling of G protein-linked receptors. Trends in Pharmacological Sciences 199011 492-499. (doi:10.1016/0165-6147(90)90050-I)

32 Konvicka K, Guarnieri F, Ballesteros JA \& Weinstein H. A proposed structure for transmembrane segment 7 of $\mathrm{G}$ protein-coupled receptors incorporating an asn-Pro/Asp-Pro motif. Biophysical Journal $1998 \mathbf{7 5}$ 601-611. (doi:10.1016/S0006-3495(98)77551-4)

33 Rodriguez MC, Xie YB, Wang H, Collison K \& Segaloff DL. Effects of truncations of the cytoplasmic tail of the luteinizing hormone/ chorionic gonadotropin receptor on receptor-mediated hormone internalization. Molecular Endocrinology 19926 327-336. (doi:10.1210/ mend.6.3.1316539)

34 Martens JW, Lumbroso S, Verhoef-Post M, Georget V, Richter-Unruh A, Szarras-Czapnik M, Romer TE, Brunner HG, Themmen AP \& Sultan C. Mutant luteinizing hormone receptors in a compound heterozygous patient with complete Leydig cell hypoplasia: abnormal processing causes signaling deficiency. Journal of Clinical Endocrinology and Metabolism 200287 2506-2513. (doi:10.1210/jcem.87.6.8523)

35 Laue L, Wu SM, Kudo M, Hsueh AJ, Cutler GB Jr, Griffin JE, Wilson JD, Brain C, Berry AC, Grant DB et al. A nonsense mutation of the human luteinizing hormone receptor gene in Leydig cell hypoplasia. Human Molecular Genetics 19954 1429-1433. (doi:10.1093/hmg/4.8.1429)

$36 \mathrm{Zhu} \mathrm{H}$, Wang $\mathrm{H} \&$ Ascoli $\mathrm{M}$. The lutropin/choriogonadotropin receptor is palmitoylated at intracellular cysteine residues. Molecular Endocrinology 19959 141-150. (doi:10.1210/mend.9.2.7776964)

37 Kawate N \& Menon KM. Palmitoylation of luteinizing hormone/ human choriogonadotropin receptors in transfected cells. Abolition of palmitoylation by mutation of Cys-621 and Cys-622 residues in the cytoplasmic tail increases ligand-induced internalization of the receptor. Journal of Biological Chemistry 1994269 30651-30658.

38 Barak LS, Menard L, Ferguson SS, Colapietro AM \& Caron MG. The conserved seven-transmembrane sequence $\mathrm{NP}(\mathrm{X}) 2,3 \mathrm{Y}$ of the G-proteincoupled receptor superfamily regulates multiple properties of the ß2-adrenergic receptor. Biochemistry 199534 15407-15414. (doi:10.1021/bi00047a003)

39 Wess J, Nanavati S, Vogel Z \& Maggio R. Functional role of proline and tryptophan residues highly conserved among $\mathrm{G}$ protein-coupled receptors studied by mutational analysis of the $\mathrm{m} 3$ muscarinic receptor. EMBO Journal 199312 331-338.

$40 \mathrm{Lu}$ ZL, Saldanha JW \& Hulme EC. Transmembrane domains 4 and 7 of the $\mathrm{M}(1)$ muscarinic acetylcholine receptor are critical for ligand binding and the receptor activation switch. Journal of Biological Chemistry 2001276 34098-34104. (doi:10.1074/jbc.M104217200)
Received 10 December 2014

Revised version received 2 March 2015

Accepted 20 March 2015 